\title{
Electro-Static Discharge Problem
}

National Cancer Institute

\section{Source}

National Cancer Institute. Electro-Static Discharge Problem. NCI Thesaurus. Code C63213.

Problem associated with the discharge of electricity between two bodies previously electrically charged. 